\title{
Correction to: Assessing the volatile profile of carob tree (Ceratonia siliqua L.)
}

\author{
Andriana Krokou $^{1} \cdot$ Marinos Stylianou $^{1} \cdot$ Agapios Agapiou $^{1}$
}

Published online: 10 April 2019

(C) Springer-Verlag GmbH Germany, part of Springer Nature 2019

\section{Correction to: Environmental Science and Pollution Research https://doi.org/10.1007/s11356-019-04664-7}

The original publication of this paper contains an error.

The correct caption of Fig. 2 is shown in this paper.

The online version of the original article can be found at https://doi.org/ 10.1007/s11356-019-04664-7

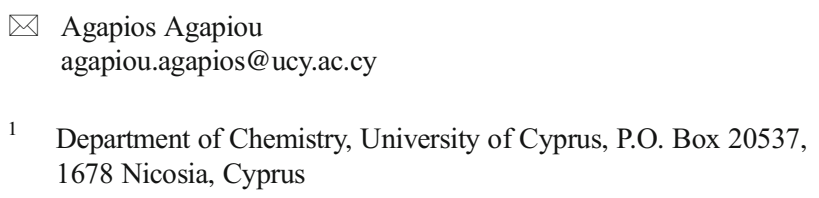




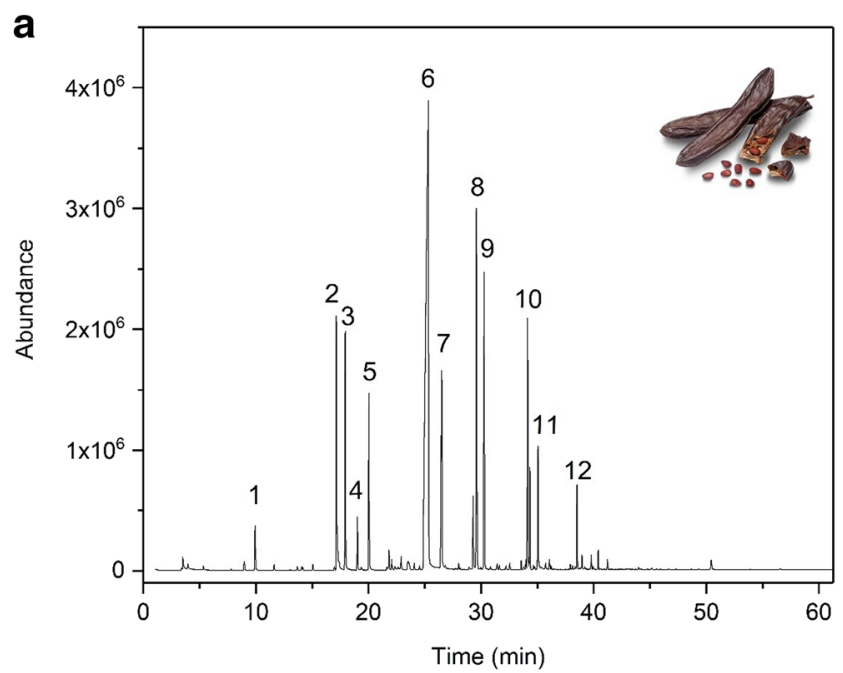

Fig. 2 Headspace SPME/GC-MS chromatogram of (a) carob fruit, (b) powder and (c) flower. The VOCs shown in chromatograms are numbered as follows: 1: Acetic acid, methyl ester, 2: Acetic acid, 3: Propanoic acid, 2-methyl, methyl ester, 4: 2-Pentanone, 5: Butanoic acid, methyl ester, 6: Propanoic acid, 2-methyl, 7: Butanoic acid, 8: 2-Heptanone, 9: Hexanoic acid, methyl ester, 10: Propanoic acid, 2-methyl, 2-methylbutyl ester, 11: Hexanoic acid, 12: 2-Nonanone, 13: Acetaldehyde, 14: Pentane, 15: Ethanol, 16: Furan, 2-methyl, 17: Ethyl acetate, 18: Butanal, 3-methyl, 19: Octane, 20: a-Pinene, 21: Eucalyptol, 22: Linalool

The original article has been corrected.

Publisher's note Springer Nature remains neutral with regard to jurisdictional claims in published maps and institutional affiliations.
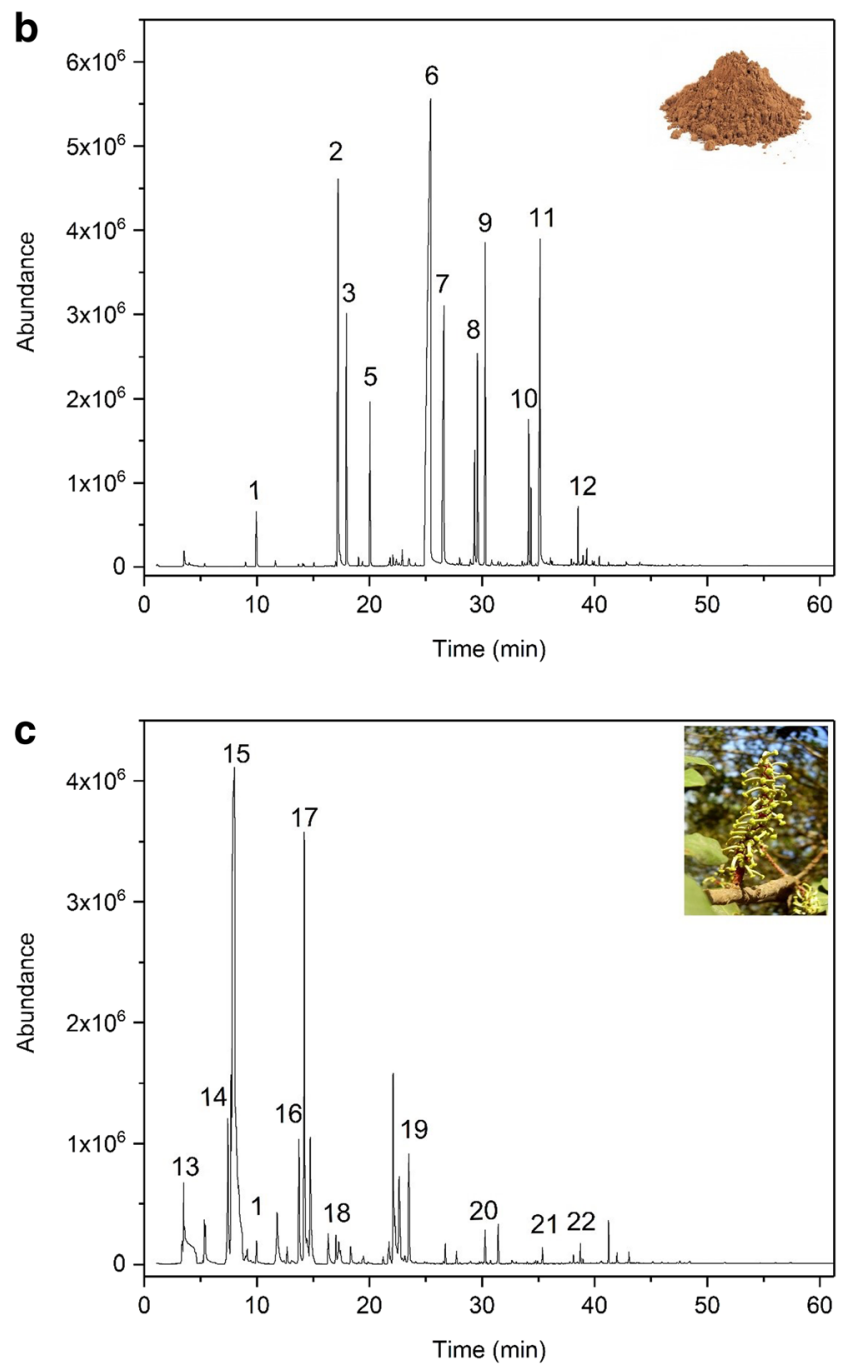